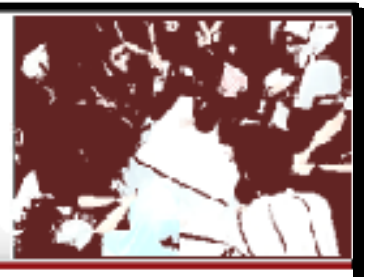

\title{
Identifying physiotherapy stakeholders for program evaluation
}

\section{Veasuvalingam Bhavani}

Physiotherapy Program Coordinator/Lecture, AIMST University, Semeling,08100 Bedong, Kedah Darul Aman, Malaysia

\section{ARTICLE INFO}

$\begin{array}{ll}\text { Received } & : 26 / 01 / 2012 \\ \text { Accepted } & : 27 / 05 / 2012 \\ \text { Published } & : 01 / 12 / 2012\end{array}$

\section{KEYWORD}

Stakeholder

Physiotherapy

Program evaluation

Allied health education

(c) Medical Education Department, School of Medical Sciences, Universiti Sains Malaysia. All rights reserved.

CORRESPONDING AUTHOR: Veasuvalingam Bhavani, Physiotherapy Program Coordinator/Lecturer AIMST University, Semeling,08100 Bedong, Kedah Darul Aman, Malaysia

Tel: 04-4298000 ext 1033, Fax: 04-4298009, Email: veasuvalingambhavani@ gmail.com 


\section{Introduction}

The Health Professional Education plays a pivotal role in providing quality health work force thus improved care in health service to the public in our country. As such all Allied Health Programs conducted by Higher Education Providers (HEP) should keep close surveillance of the quality of Allied Health Programs to mould health professional graduates to deliver quality healthcare service through proper competency measures. Stakeholders have been defined as on-campus and off campus group for the sake of identifying respective views in institutional effectiveness (1).

Allied health programs are emerging enormously in our country and this revolution is creating major crustal deformation, forming folds and faults towards its profession as many educational institutions in the country is with the enterprising objectives of running such programs and not for the benefits of the society.

\section{AIMST Physiotherapy Program}

The Diploma in Physiotherapy (Dip. PT) at AIMST University Semeling, Kedah has been established for the past 5 years. The School of Physiotherapy at AIMST has been continuously striving to improve its Diploma Program to ensure its graduates are competent and credible enough to top and tail the panorama of clinical challenges which requires a myriad of attributes which is essential for health professionals to posses in order to survive in the health industry. In order to achieve this objective, evaluation should stand as part of any educational system. The purpose of evaluation is to seek understanding specifically as to why changes take place. Furthermore, evaluation reveals the actual effectiveness of using the professional time and benefits to clients (4).

\section{Multistage program evaluation process}

Since, program evaluation could take place at multiple stages; stakeholders would also significantly differ at various stages of the evaluation process. Evaluation can be conducted when planning a new program, assessing a developing program, assessing a stable and mature program as well as at the completion of the program. The school of physiotherapy focuses on conducting its evaluation at various stages of its program and the information acquired from the stakeholders is given due importance to make the necessary changes. Thus formative evaluation should be one of the school's instruments for the purpose of achieving this means. The main goal of the School of Physiotherapy is to produce highly competent physiotherapy graduates. This is accomplished through learning focused and centering towards students outcomes through its assessment which acts by itself as a feedback loop to our school on efficiency of our educational objectives as stated by Praslova L (3).

\section{The open system theory}

Suggestion made by educational institution to make continuous amendments and improvements to enhance its program through the open systems theory, whereby the institution connects itself to the outside world in various aspects in order to receive feedback (3). This according to him will maintain the relevancy of the program in this constantly evolving globe. As for that purpose, the school gives due thought to stakeholders from every perspective. Everyone whose lives are affected by the program are given due consideration openly to ensure the transparency of the program is maintained. This two way communication system made symbiosis to one another for the betterment of everyone.

\section{Global changes in healthcare and disease pattern}

As there is a continuum of change in global healthcare and diseases, so is the societal demand for health care delivery. The school's program objectives (PO) is spelled with the goal of achieving end product desired with the current need especially graduates who is clinically competent who have a myriad of skills important for a competent physiotherapist such as good communication skills, analytical thinking, social skills, working in a team since 
physiotherapy is multidisciplinary. The school focuses in cultivating graduates in line with one of our main stakeholder the Malaysian Qualification Agency (MQA's) \& 8 Malaysian Qualification Framework (MQF).MQF is the measurement tool that defines qualification in hierarchy for any given educational program in the country. MQA works very closely with the health education providers in designing its quality program. These qualification framework interpreted in health context describes the clinical competency that is very much demanded by the society.

\section{Stakeholders for physiotherapy program}

Identifying stakeholders of the Diploma in Physiotherapy program takes a different pictorial view at AIMST. The school defines local preceptors at the government hospitals whom are actively involved in the students' clinical education and the academic staffs of the school as key stakeholders whom are involved in the program operations. On the other hand, students, parents, community groups and social networks whom are our non-governmental organizations (NGO's) such as the NASAM (National Stroke Associations) or the Spastic Centers are stakeholders whom the program serves at its best as well as intended users of the evaluation findings. Prospective employers who range from government hospital, private health providers as well as the accreditation body, the Malaysian Qualifying Agency (MQA) are the main intended users of evaluation findings.

The MQA has an overlapping function as both involvements in program operation and intended users of evaluation findings. Similar scenario goes to our policy makers, the Ministry of Higher Education (Kementerian Pengajian Tinggi $-\mathrm{KPT}$ ) and Ministry of Health $-\mathrm{MOH}$. Furthermore the evaluation findings facilitate in benchmarking and decision making of several policies. Despite MQA's effort in screening programs to meet the expected standards prior conferment of certification of accreditation to all educational programs in the country through its mandatory regulation, political bureaucracies is inevitable in taking a significant toll.
Recent policy circulated by the KPT to all higher education providers was the monotarium to bar all newly emerging educational institutions to run physiotherapy and nursing programs. This was a step taken to curb the high unemployment rate of qualified health professional graduates churned by various institutions which is growing exponentially in an alarming state in the country.

The latter two stakeholders (KPT and $\mathrm{MOH}$ ) points to student learning and program outcomes as the top most important criteria (3).MQA highly values evaluation findings especially from the students and local preceptors as key to a good program implementation. AIMST University senior management teams are also our internal stakeholders for our program who uses the evaluation findings to make decision on funding the program and in providing continuous support for the school. As one of the key funding body in the country, Perbadanan Tabung Pendidikan Tinggi Nasional (PTPTN) also has a major interest in students' academic achievement to continuously provide educational loans to excelling students. PTPTN has specifically fixed its criteria for sanctioning its loan by the Grade Point Average (GPA) as an indicator of student progress in order to release its fund.

\section{Primary and secondary stakeholders}

As for the School of Physiotherapy at AIMST University, our students are our main stakeholders whom are very much affected by the program. The school maximizes all its potentials to enhance the credibility of our graduates through educational effectiveness by meeting its program objectives. The evaluation findings obtained from students who define the success of physiotherapy program is highly valued and changes are made in an attempt to improve the program from the students' perspective. Secondly our academic staffs whom are directly involved in the continuous changes of program implementation are critical in defining the problems as it arises. These two stakeholders' (students and staffs) seems to play a key role in enhancing the credibility of the program by and large. 
Furthermore, the intended users of our evaluation findings, the KPT and $\mathrm{MOH}$ advocates and outlines policies based on the data interpreted. These include the mandatory implementation of the program criteria such as entry requirements, maximum and minimum duration of program, maximum credits per semester and etc. In addition to this, PTPTN, key to sustainability of the program, is a driving factor in students' enrollment. Thus the impact of evaluation findings has a major repercussion to its continuous support.

\section{Evaluation tools}

The school uses multiple evaluation strategies to obtain information to keep the above mentioned stakeholders engaged. Our prospective students are connected through the teaching evaluation forms which are used by the end of every semester. The school alumni feedback survey forms, is another mechanism utilized to obtain feedback of the program upon completion. Hospital local preceptors are given the clinical assessment feedback forms and the feedback is then used to make changes and improvement as the program is running. Surveys and interviews are held periodically to continuously obtain input of the program implementations and its logistical issues are discussed. The evaluation findings are processed and focus group discussion is organized to develop strategies to make improvement. Communicating the evaluation findings to the stakeholders in a meaningful way is essential in order to improve one's program (2).This phenomenon seeks for key stakeholders of a particular program to engage diplomatically with the school to genuinely contribute and provide accurate information.

Those stakeholders whom are directly involved in program operations such as the academic staffs and external examiners, should hold curriculum committee meetings periodically to discuss and deliberate on the content of curriculum that is delivered to the students. In addition MQA who authorizes institutions to run the program by issuing the provisional accreditation for 3 years period ought to correspond on any changes and amendments made to the curriculum. During the final year of the first cohort prior graduation, the MQA conducts its final accreditation visit and upon its satisfaction grants the full accreditation to run the program. This is achieved via evaluation findings submitted by the school as part of our quality assurance process. Thus the MQA's engagement with the program starts from the very beginning when the documentation of the curriculum is submitted for approval process till the conferment of full accreditation.

\section{Conclusion}

In a nutshell, as the health educational programs are an ongoing process, so is the program evaluation. In order to conduct an educational program that meets the current societal needs and preferences, the curriculum, teaching and learning activity as well as the assessments should synchronize. Feedback is crucial and it should be taken more seriously by educational institutions in the country. In order to stay current with the evolving global and local expectation, program evaluation promises a desirable approach as part of the program implementation to ensure the delivery of knowledge addresses and facilitates real life experiences.

\section{Reference}

1. Hom WC. Stakeholders in the institutional effectiveness process - new direction for community colleges, 2011 Wiley Periodicals, Inc. DOI: 10.1002/cc.439.

2. Lorena L, Julie S. Using program evaluation to inform and improve the education of young English language learners in US schools. Language Teaching Research. 2009; 35-5413-1.

3. Praslova L. Adaptation of Kirkpatrick's four level model of training criteria to assessment of learning outcomes and program evaluation in Higher Education. Educ, Asse, Eval \& Acc. 2010; 215-225-22.

4. Waters KR. The importance of program evaluation: a case study. Journal of Human Services. 2011; 83-93-31. 